\title{
RESIN FLOW SIMULATION DURING THE RTM METHOD OF COMPOSITES PRODUCTION
}

\author{
Pawel Paździor, Miroslaw Szczepanik \\ Silesian University of Technology, Faculty of Mechanical Engineering, \\ Department of Computational Mechanics and Engineering \\ 44-100 Gliwice, Poland
}

Corresponding author: Pawel Paździor. pawel.pazdzior@racing.polsl.pl

\begin{abstract}
Processes of plastic injection molding are often under analyzes in industry and science. Many of these considerations apply to epoxy resins with additional reinforcement, often with glass or carbon fiber inside the closed mould. The simulations of injection molding processes in the production of composite elements is not as common, as thermoplasts. Hence the idea to carry out the work described in this article. The RTM (Resin Transfer Molding) method is dedicated to serial production with the possibility of producing visual carbon fiber elements for aesthetic reasons. Simulations can help to better refine the products. This allows to take appropriate precautions and solve many issues before implementation. The article presents possible situations that could occur in real conditions. Various shapes models were prepared as basis of the numerical calculations. The analyses highlighting the possible issues were performed. The influence of resin pressure and flow rate on the final product was also considered. The aim was to present the characteristic phenomena and their causes that often occur in reality to technologists working with the RTM. Conclusions related to the work carried out are included. Based on the analyzes and conclusions drawn, it is possible to improve the quality of production processes.
\end{abstract}

Key words: RTM, simulation, computational analysis, moldflow, composites, FEM.

\section{INTRODUCTION}

Thanks to a broad spectrum of implementations, and to multiple production and combination methods composites are implemented in many industries. [1] The choice of the appropriate technology and material in the production enables achieving gratifying effects $[2,3]$.

Automotive market requires modern product design, high dimensional accuracy and surface quality, thus generating new challenges in manufacturing technologies. This process leads to new and innovative solutions which cover the entire life cycle of the product, in particular the design and manufacturing process [4]. The paper concentrates on simulating flow of epoxy resin in injection mold with carbon fiber inside. Simulations were carried out using the advanced RTM (Resin Transfer Molding) method to produce composite components. It involves injecting resin into a closed, reinforcing form under pressure. One of the main issues of this technique is to provide appropriate resin flow in the injection mold and fully supersaturate the reinforcement with thermosetting resin. Directions of carbon fibers and porosity of reinforcement heavily affects these attributes. Numerical simulations can generate information on correct design of the mold and the impact of fiber orientation and porosity using professional CFD software Moldex3D. Investigation was focused on real production method of mirror caps for sport cars.

\subsection{RTM process overview}

The RTM (Resin Transfer Molding) method is a closed mold method to manufacture carbon fiberbased composites. It involves the injection of resin into the preset reinforcement. [5] Resin, reinforcement and technological characteristics heavily affect the properties of the produced parts. The performance of the finished workpiece also is under effect of environmental pressure and temperature, reinforcement size and its distribution [6]. Many factors affecting the manufacturing method need simulation software at the planning point. Simulations allow to choose the injection speed and determine the time of filling the mold. Too low injection speed may not allow the resin to fully saturate the reinforcement due to premature hardening, whereas too high injection speed may move reinforcement inside the mold [5]. Placement of reinforcement within the mold is also important. The uneven allocation in the cavity volume contributes to many adverse effects: the complete fulfilling is not allowable and increase strain forces which deform the part $[7,5,8]$. 
One of present targets is to implement innovative technology to decrease the cost of producing carbon fiber parts and unlock the chance of mass production. [9]Developing components by using the RTM method generates multiple issues described in the next section of this paper.

The RTM method is mainly used for serial production, because it's economically justified only for large volumes [10]. This is due to the relatively high costs of starting production and relatively low unit production costs. In comparison with other methods of production of composite elements, the RTM method allows high repeatability and production efficiency [11]. RTM is much safer for employees and the environment due to the smaller amount of styrene emitted to the atmosphere. This effect is obtained by isolating the gelling process from the environment by using a closed mold.

The RTM production process involves injection of resin mixture into the mold with reinforcement. This method of production is used to manufacture high quality components, meeting strict requirements in terms of strength and aesthetics. By using a closed mold, it is possible to obtain smooth surfaces or textures corresponding to the mold surface on both sides of the molding. It is also possible to manufacture elements of any size and complex shapes. Thanks to the closed form, elements manufactured by RTM are characterized by high dimensional accuracy. In order to improve the manufacturing process vacuum is often used, as it allows to control the flow of the resin material and is helpful in accurately closing the mold. A simplified diagram of the RTM process implementation is presented in the Figure 1.

\subsection{Matrix material}

The finite element analysis was carried out for the chosen model of thermosetting, epoxy resin material. Figure 2 and 3 shows resin's viscosity and conversion graphs [12] and Table 1 and 2 shown input parameters of the process.

The properties of the reinforcement material have no major impact on the course of the process being analyzed. Used type of fabric or mat determines the production characteristics (such as thickness, density or type of weave) and the positioning of the reinforcement in the mold. The influence of reinforcement parameters for the needs of numerical simulations was described by three variables. The first variable - porosity refers to the volume occupied by the reinforcement in the form. The variable takes values in the range $<0,1>$. Where porosity 0 means complete filling of the form by reinforcement, and 1 means absolute lack of reinforcement in the form. The second variable - the permeability is strongly anisotropic. The third one is the directions of permeability.

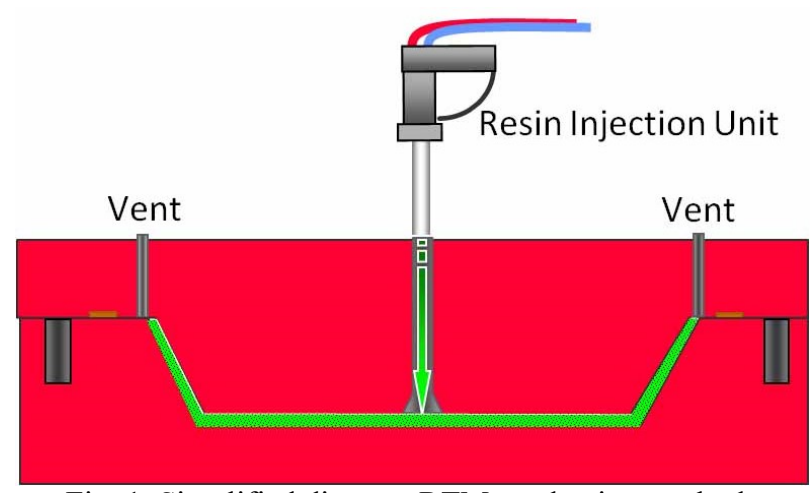

Fig. 1. Simplified diagram RTM production method

Table 1. Suggested process conditions

\begin{tabular}{|c|c|}
\hline Melt temp. (min) & $20{ }^{\circ} \mathrm{C}$ \\
\hline Melt temp. (normal) & $25{ }^{\circ} \mathrm{C}$ \\
\hline Melt temp. (max) & $30{ }^{\circ} \mathrm{C}$ \\
\hline Mold temp. (min) & $30{ }^{\circ} \mathrm{C}$ \\
\hline Mold temp. (normal) & $35{ }^{\circ} \mathrm{C}$ \\
\hline Mold temp. (max) & $40{ }^{\circ} \mathrm{C}$ \\
\hline Melt temp. (min) & $20{ }^{\circ} \mathrm{C}$ \\
\hline Melt temp. (normal) & $25{ }^{\circ} \mathrm{C}$ \\
\hline Melt temp. (max) & $30{ }^{\circ} \mathrm{C}$ \\
\hline
\end{tabular}

Table 2. Mechanical properties of epoxy resin

\begin{tabular}{|c|c|}
\hline Poisson's ratio & 0.38 \\
\hline Young's modulus & $2 \mathrm{e} 9 \mathrm{~N} / \mathrm{m}^{2}$ \\
\hline Kirchhoff module & $5.7 \mathrm{e} 8 \mathrm{~N} / \mathrm{m}^{2}$ \\
\hline $\begin{array}{c}\text { Coefficient of linear thermal } \\
\text { expansion (fiber direction) }\end{array}$ & $9 \mathrm{e}-6$ \\
\hline $\begin{array}{c}\text { Coefficient of linear thermal } \\
\text { expansion (perpendicular direction) }\end{array}$ & $4.5 \mathrm{e}-5$ \\
\hline
\end{tabular}

Epoxy 2511-1A/BS SWANCOR Shear Rate $=1.01 / \mathrm{sec}$

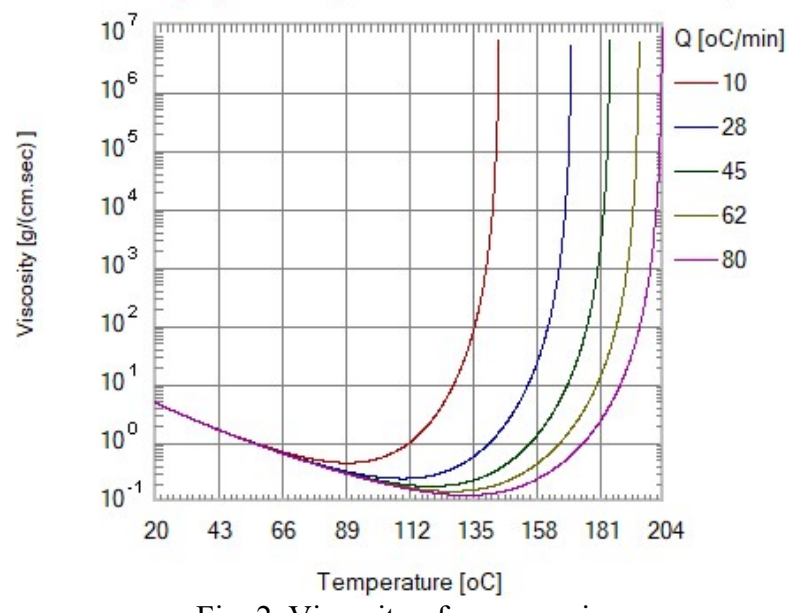

Fig. 2. Viscosity of epoxy resin 


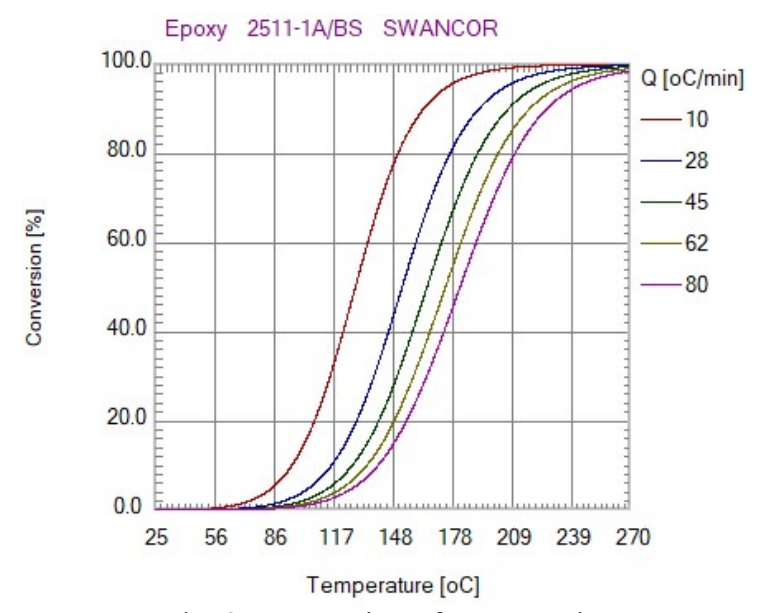

Fig. 3. Conversion of epoxy resin

\section{SIMULATION AND ANALYSIS}

A flow rate adjustment is used for the resin injection control. It averages around $0.7 \quad \mathrm{~cm}^{3} / \mathrm{s}$ The documentation defines maximum inlet pressure of $7 \mathrm{MPa}$, corresponding to the resin injection machine specifications. Data was presented in Table 3.

Table 3. Input parameters in the simulation process

\begin{tabular}{|c|c|}
\hline Max. filling time & $600.00 \mathrm{~s}$ \\
\hline Inlet material temperature & $25.0^{\circ} \mathrm{C}$ \\
\hline Mold temperature & $35.0^{\circ} \mathrm{C}$ \\
\hline Max. injection pressure & $7.00 \mathrm{MPa}$ \\
\hline Max. inlet flow rate & $0.7 \mathrm{~cm}^{3} / \mathrm{s}$ \\
\hline Cavity volume & $173.614 \mathrm{~cm}^{3}$ \\
\hline Environment temp. & $25.0^{\circ} \mathrm{C}$ \\
\hline
\end{tabular}

\subsection{Mathematical description}

Simulations were carried out, the aim was to analyze the impact different variants and type of reinforcement arrangement in the mold cavity have on the resin flow. The flow of resin in the mold determined by the pressure difference between two points inside the mold (Figure 4).

$$
\boldsymbol{K}=\left[\begin{array}{lll}
K_{x x} & K_{x y} & K_{x z} \\
K_{y x} & K_{y y} & K_{y z} \\
K_{z x} & K_{z y} & K_{z z}
\end{array}\right]=\left[\begin{array}{lll}
l_{11} & l_{12} & l_{13} \\
l_{21} & l_{22} & l_{22} \\
l_{31} & l_{32} & l_{33}
\end{array}\right]\left[\begin{array}{ccc}
K_{11} & 0 & 0 \\
0 & K_{22} & 0 \\
0 & 0 & K_{33}
\end{array}\right]\left[\begin{array}{lll}
l_{11} & l_{21} & l_{31} \\
l_{12} & l_{22} & l_{22} \\
l_{13} & l_{23} & l_{33}
\end{array}\right]
$$

$K_{11}, K_{22}, K_{33}-$ main directions of permeability tensor. The main directions of the permeability tensor are the input data for simulation in the Moldex3D software determine the elements lij of the above matrix. $l_{i j}$ - The main values of the permeability tensor $K_{i j}$ - Permeability of the main axes of permeability tensor

The flow continuity equation (equation 4) is expressed as follows:

$$
\frac{\partial p}{\partial t}+\nabla \cdot(\rho u)=0
$$

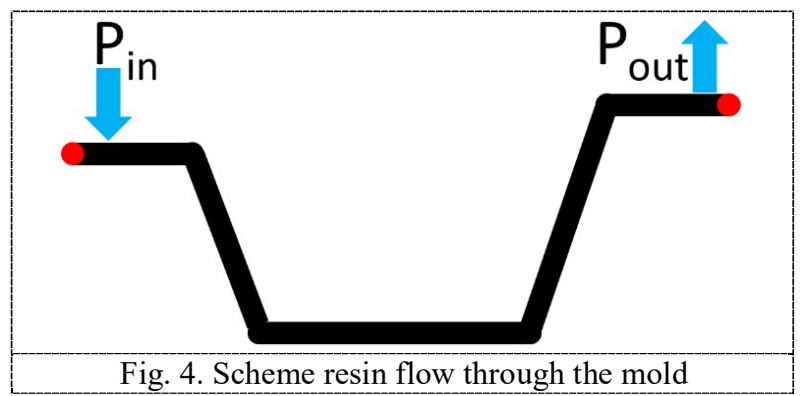

The flow of resin in any injection method can be described in simplified terms using the Darcy's law (equation 1). Taking into account the difference in pressure in the formula, injection time, resin viscosity and permeability, we can observe the influence of given factors on the flow.

$\boldsymbol{t}$ - injection time,

$$
t=\frac{l^{2} \cdot A}{2 \cdot K^{2} \cdot A P}
$$

$A$ - resin viscosity (lower viscosity make injection shorten),

$\boldsymbol{l}$ - element length (small distance between inlet and outlet shortens time),

$\boldsymbol{K}$ - permeability tensor (larger, shortens the time of injection),

$\Delta P$ - pressure difference (higher, make injection time shorten).

The flow velocity vector takes the form (equation 2).

$\boldsymbol{u}$ - velocity,

$$
\boldsymbol{u}=-\frac{\boldsymbol{K}}{\eta} \nabla p
$$

$\eta$ - viscosity,

$\nabla p$ - pressure gradient.

The permeability of the carbon reinforcement inside the mold can be defined using a permeability tensor (equation 3). It is a matrix $\mathrm{K}$, which we define by giving the values $\mathrm{K}_{11}, \mathrm{~K}_{22}, \mathrm{~K}_{33}$.

$\rho$ - fluid density and the energy equation (equation 5) takes the following form:

$$
\frac{\partial}{\partial t}\left(\rho C_{p} T\right)+\nabla \cdot\left(\rho u C_{p} T\right)=k \nabla^{2} T+\eta \dot{\gamma}+\emptyset \frac{d a}{d t} \Delta H
$$

$C_{x}$-specific heat,

$T$ - temperature,

$k$ - thermal conductivity,

$\dot{\gamma}$-shear rate,

$\alpha$ - conversion,

$\Delta H$ - heat gain from chemical reactions. 
In order to determine viscosity of the resin, a modified Castro-Macosko model was used [13-15]. This mathematical model is often used for curing the liquid thermosetting described as thermo-physical transport equation (equations 6 and 7).

$$
\begin{gathered}
\eta(T, \dot{\gamma}, c)=\frac{\eta_{0}}{1+\left(\frac{\eta_{0} \cdot y}{T^{*}}\right)^{1-n}}\left(\frac{c_{g}}{a_{G-a}}\right)^{c 1+c 2 a} \\
\eta_{0}(T)=A \cdot \exp \left(\frac{T_{b}}{T}\right)
\end{gathered}
$$

$\eta_{0}-$ viscosity without shearing

$\alpha_{g}$ - gelation point.

$\tau^{*}, c 1, c 2, n, B, T b-$ material constants.

Combined model of Kamal, Sourour and Ryan (equations 8 and 9) was used to describe the cure in viscoelastic relations [16].

$$
\begin{aligned}
& \frac{d a}{d t}=k_{T} \alpha^{m}(1-\alpha)^{n} \\
& k_{T}=C \cdot \exp \left(\frac{-Q}{R \sigma}\right)
\end{aligned}
$$

$m, n$ - material coefficients,

$k_{T}$ - reaction rate that can be described by the Arrhenius equation,

$C$ - coefficient of proportionality,

$Q-$ activation energy,

$R$ - gas constant,

$T$ - temperatura.

\subsection{Mesh}

Performed tests were based on a $3 \mathrm{D}$ model of the cover of car mirrors. The major subject of studies was to simulate the flow of resin in the cavity and evaluate the injection parameters impacts on the right procedure. The cavity model included regions of the two car mirror caps geometry (right and left) (Figure 5). Mirror caps of one set are trimmed off from each mold during manufacturing. In the processes of production of RTM elements, Moldex3D software was used to simulate resin flow in the mold. This instrument is commonly used in the plastic element manufacturing sectors. The simulation of thermoplastic and reactive polymers can be performed as well. This analysis uses the finite element method computation [17]. A mesh of 3D elements with a maximum edge length limited to $3 \mathrm{~mm}$ was created (Figure 6). After the meshing process was completed, a model with the parameters described in Table 4 was received [16, 18, 19].
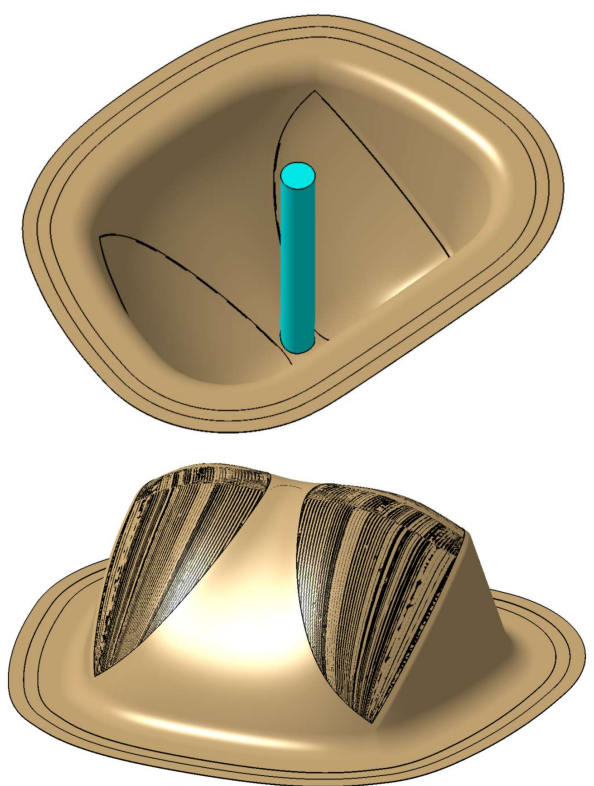

Fig. 5. CAD model of the mirror cover and the cavity model with the inlet

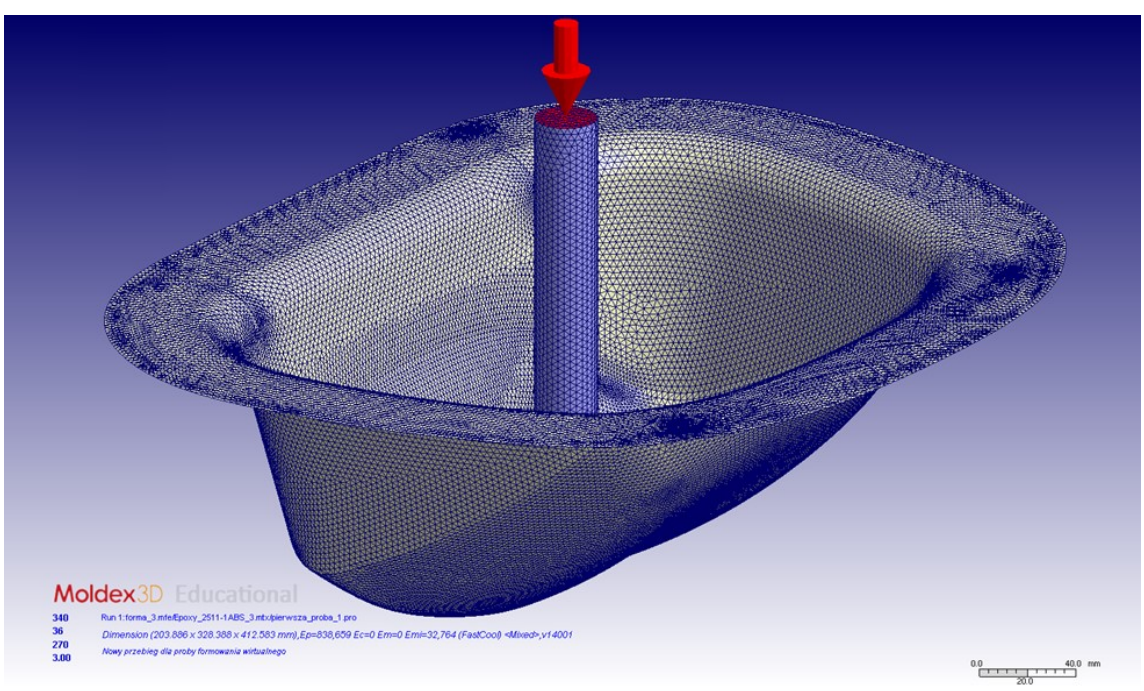

Fig. 6. Mesh of finite elements - model of the mold cavity with the inlet channel 
Table 4. Mesh of finite elements

\begin{tabular}{|c|c|}
\hline Name & Value \\
\hline Mesh type & Mixed \\
\hline Cavity dimension & $\begin{array}{c}137.1177 \times 328.3881 \times \\
412.5835(\mathrm{~mm})\end{array}$ \\
\hline Mold dimension & $\begin{array}{c}214.2700 \times 375.0000 \times \\
460.0000(\mathrm{~mm})\end{array}$ \\
\hline Cavity volume & $69.2558\left(\mathrm{~cm}^{3}\right)$ \\
\hline Runner volume & $104.358\left(\mathrm{~cm}^{3}\right)$ \\
\hline $\begin{array}{c}\text { Total number of finite } \\
\text { elements }\end{array}$ & 871423 \\
\hline $\begin{array}{c}\text { Cavity number of finite } \\
\text { elements }\end{array}$ & 838659 \\
\hline $\begin{array}{c}\text { Nodes number } \\
\text { The maximum size of finite } \\
\text { elements }\end{array}$ & 368756 \\
\hline
\end{tabular}

\section{SIMULATION AND ANALYSIS}

Multiple numerical analyses were performed. Various factors influencing epoxy resin flow in the mold with the fabric and the occurrence of undesired events were taken into consideration. Air traps have been the most problematic among many of the negative events. The model was evaluated with regard to the impact of the reinforcement parameter with the same carbon fabric location and the impact of the carbon fabric arrangement with equivalent reinforcement parameters.

\subsection{The undesirable phenomena of the filling process}

An important issue in the design is venting of the mold in such a way that after the injection process the reinforcement is fully saturated by the resin without air bubbles. Excess resin in the mold is transferred through the overflow channel. A deficiency of resin causes a failure that can be easily corrected by increasing the volume of resin injected. If, despite the increase in the amount of injected resin, the failures still occur, they are called air traps. They emerge in a situation when the flowing front separates and then connects back in another place (Figure 7). In this situation, the undesirable phenomenon associated with improper filling by the resin is the phenomenon of air staying within the mold in the form of air traps. This is related to the arrangement of the reinforcement inside the $\backslash$ mold cavity and the flow resistance determined by them depending on the direction of flow and geometry of the mold cavity [20].

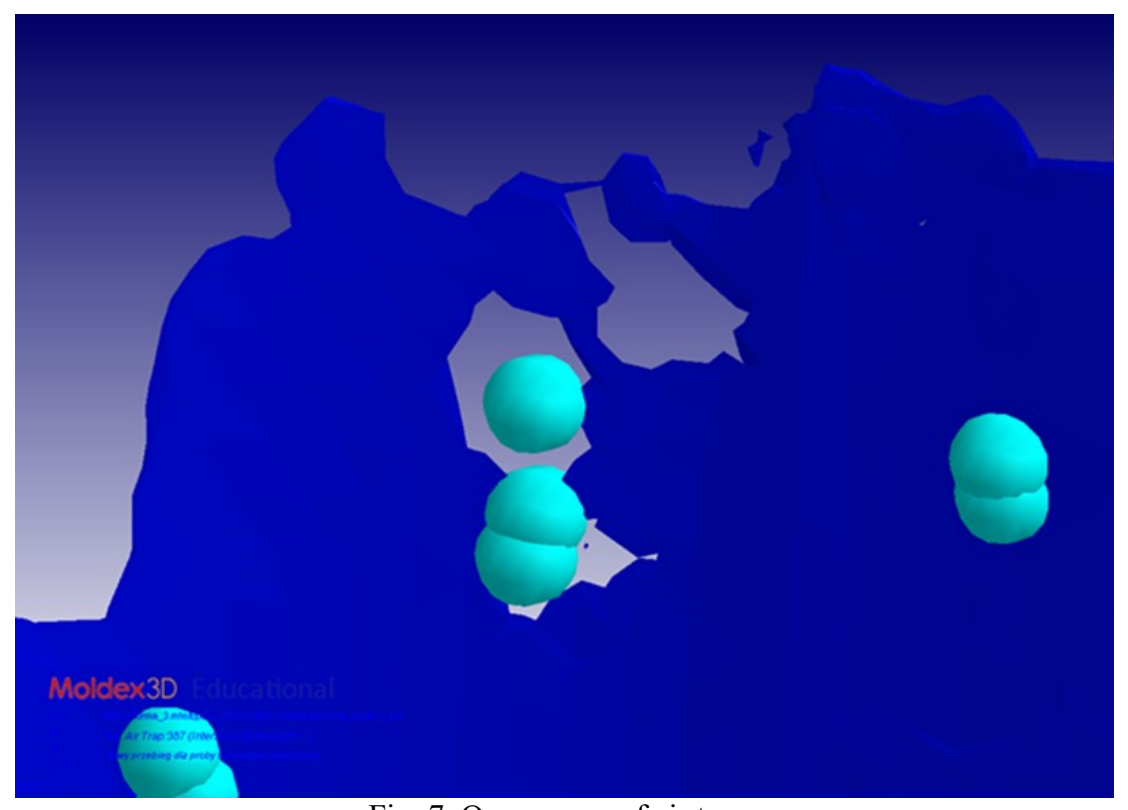

Fig. 7. Occurrence of air traps

After the flow simulation, information about the occurrence of this undesirable phenomenon was received. An air trap occurred in 387 places.
Most of the air traps appeared in the area of the collar (outside the specific area of the molded part, which is later removed as waste) as in Figure 8. 


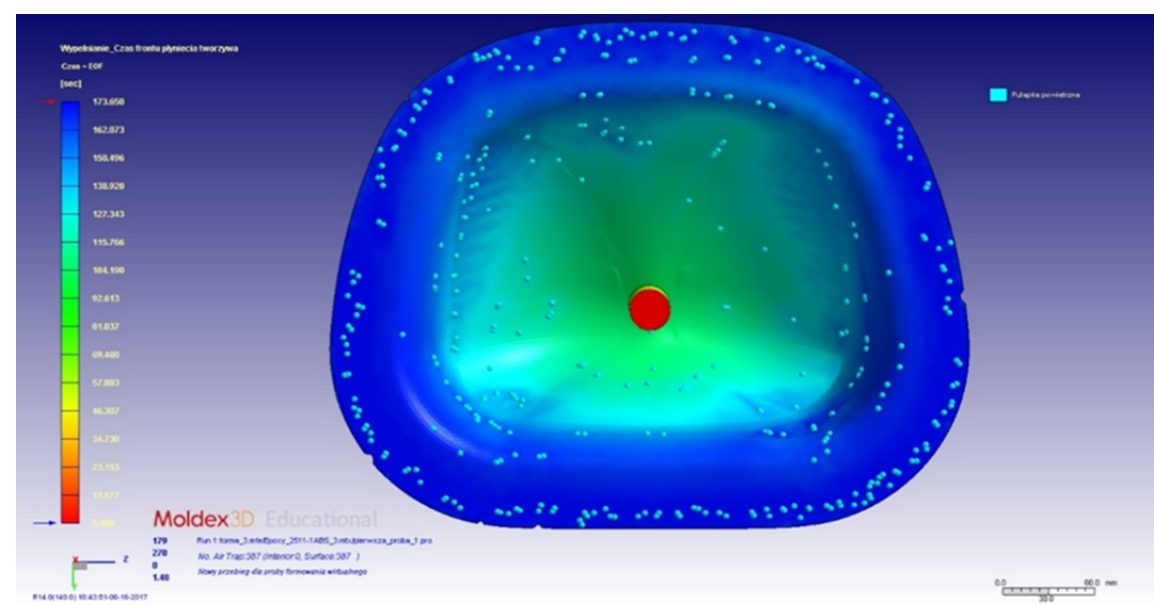

Fig. 8. A colorful map the time of cavity filling with the marked location of air traps

\subsection{Influence of reinforcement parameters}

\subsubsection{Change in porosity}

Porosity was defined as a ratio of the free space, intended to be filled with resin, to the entire volume of the mold cavity. Table 5 shows the results of simulation for selected cases of porosity of carbon fabric. The porosity unfortunately depends heavily on the fiber arrangement in the mold. Manual reinforcement identifies many adverse occurrences, including fiberdensity modifications on $1 \mathrm{~cm}^{2}$ and swings in porosity within reinforcement and greater laminated-surface distortion. The models presumed that the reinforcement parameters are stable in the whole cavity.

When analyzing the outcomes listed above, the major differences in the mold fulfilling moment are easily noticed. This must done by filling with fixed amount of resin. This indicates that the rate of injection depends heavily on how much free space it can fill in the mold.
In all cases of porosity, the number of air traps is similar, with the minimum benefit for a model with a higher fiber content. This indicates a poor dependency between the occurrence of air traps and porosity of the fabric.

In each case analyzed a similar pressure distribution was observed and the maximum pressure value increased slightly with the fabric porosity increasing. The thermal energy generated (by viscous friction) has not exceeded $0.018 \mathrm{~J}$ and $0.014 \mathrm{~J}$ respectively with a reinforcing porosity of level 0.7 or 0.5 . If the porosity is reduced to 0.2 , the energy rises to $0.273 \mathrm{~J}$. There is a bigger flow resistance to the fluid. This provides approximately 17 higher values in comparison to value researched in the past. This increase takes place only locally, the pressure distribution in most fields is comparable to other cases. This may show that the flow resistance must be overcome in regions where the mold walls are almost vertical.

Table 5. Comparison of differences in simulation with changes in porosity

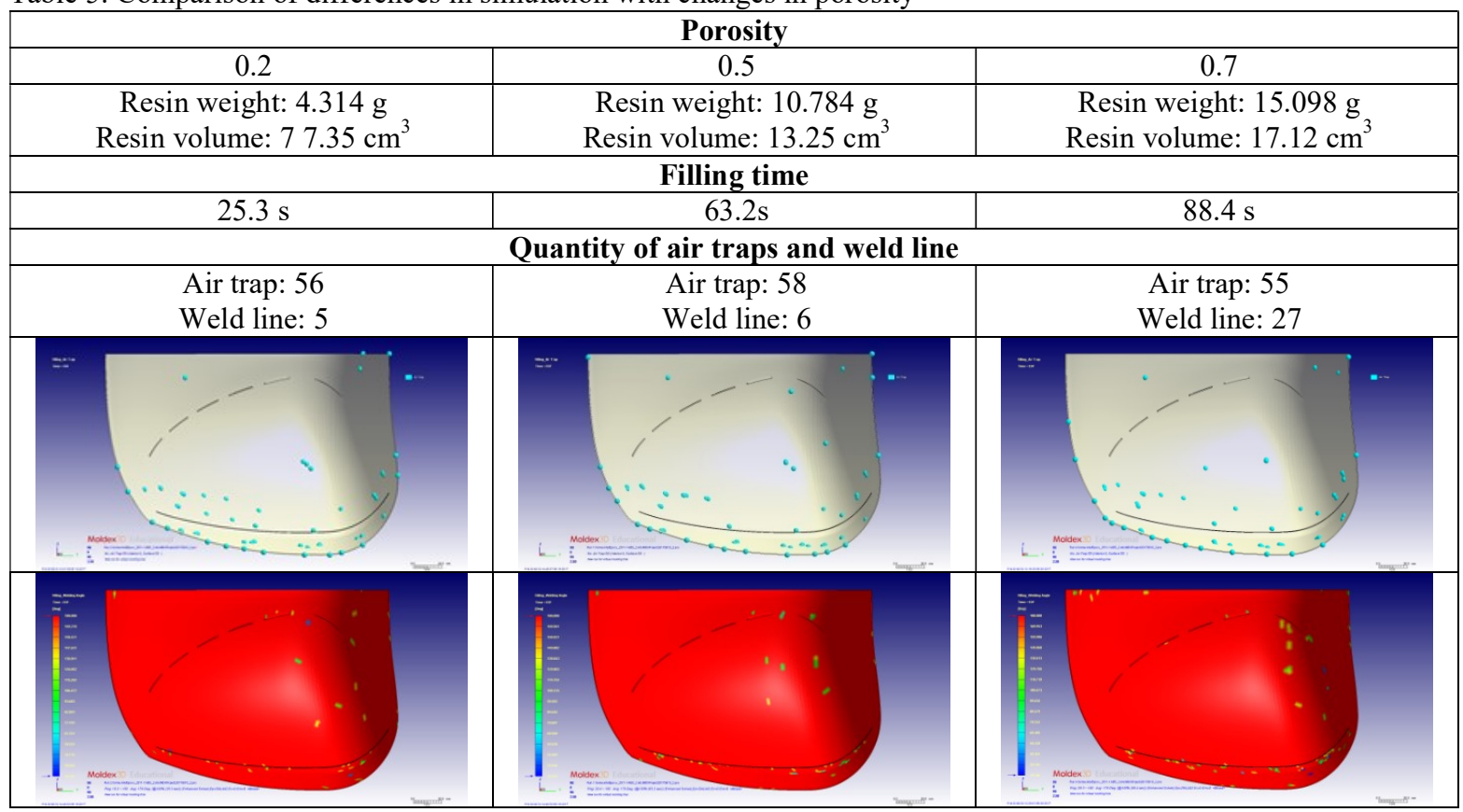




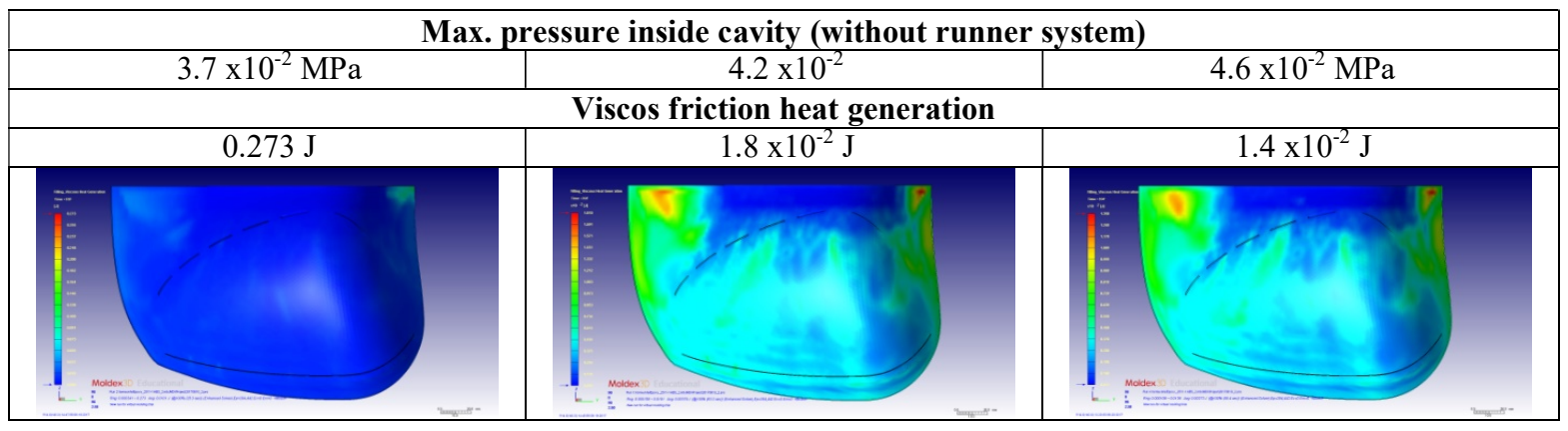

\subsubsection{Change of fiber direction}

The Resin flow relies heavily on the orientation of fibers in the mold. The orientation and the permeability of the reinforcement highly influence the resins flow. Figure 9 (a) show a flat plate with four different reinforcement areas with the same permeability in difference direction, $45^{\circ}$ to the left, $45^{\circ}$ to the right, vertically and horizontally, as shown. Figure 9 (b) shows the results of injection analysis. The location of the primary permeability axis can be considered to have a great impact that strongly determines the distribution of the resin in a plate covered with reinforcement.

The modeling of resin flow through reinforcement with characteristic porosity and permeability is slightly simplified, as fabric fibers are arranged in the same pattern over the mold. The linearity of fibers in the reinforcement is often troublesome and the material fabrics are compressed or stretched.

A study of the influence of the direction of the fiber was started by simulating a situation where the directional parameters are adequately: $\mathrm{R} 1=(0 ; 1 ; 0)$ and $\mathrm{R} 2=(0 ; 0 ; 1)$ with the assumed values of the coefficients K_11, K_22, K_33 $=0.00001 \mathrm{~cm}^{2}$. Further calculations were carried out with a constant porosity parameter equal to 0.5 , the impact of which was described in the previous section. When values $\mathrm{K} \_11, \mathrm{~K} \_22, \mathrm{~K} \_33$ are increased to $0.001 \mathrm{~cm}^{2}$, many adverse events have been reported. First of all, there have been more than 100 places with this variation of permeability where the so-called "high probability" of air traps occurring. In addition, more than 5\% of volume was not sufficiently filled.

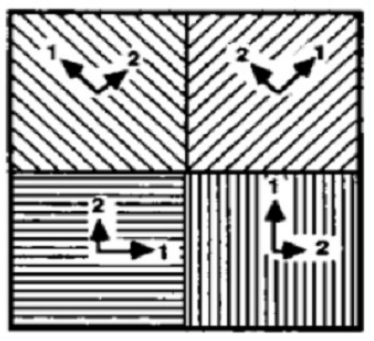

(a)

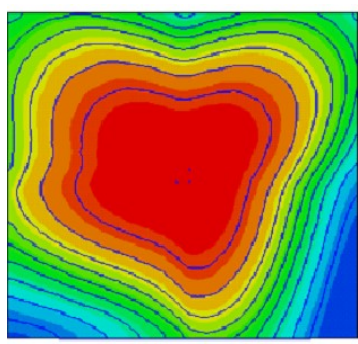

(b)
Fig. 9. The influence of the reinforcement fibers angle on the resin flow in the cavity $[13,21]$
A resin flow test has also been carried out in the form of fibers rotated by an angle of $45^{\circ}$ and the parameters $\mathrm{R} 1=(0 ; 1 ; 0)$ and $\mathrm{R} 2=(0 ; 0 ; 0)$ are relative to the output $\mathrm{R} 1=(0 ; 1 ; 0), \mathrm{r} 2=(0 ; 0 ; 1)$. The porosity parameter was unchanged at 0.5 . The variation in permeability is defined by changing the values of $\mathrm{K} \_11=0.001 \mathrm{~cm}^{2}$, K $22=0.0001 \mathrm{~cm}^{2}$ and $\mathrm{K} \_33=$ $0.00001 \mathrm{~cm}^{2}$ Terms K_11, K_22, K_33 $=0.00001 \mathrm{~cm}^{2}$. This way, only one privileged flow direction was obtained. Figure 10 shows the completeness of the after $85.2 \%$ of total filling time for two cases: a) with two equivalent directions of permeability; b) One main direction as described in above.

It is easy to notice that if there is one main permeability direction, the resin front is definitely ahead of other flow directions. This tendency is particularly noticeable in case of flat parts of the molds.

In spite of many tests involving different reinforcement in the slot, the filling time of the mold was always within the range of 100-110 seconds. In trials in which the reinforcement did not show one of the main directions of transmission, the direction of the flow resin was more prone to gravity and slowly filled the vertical walls of the mold.

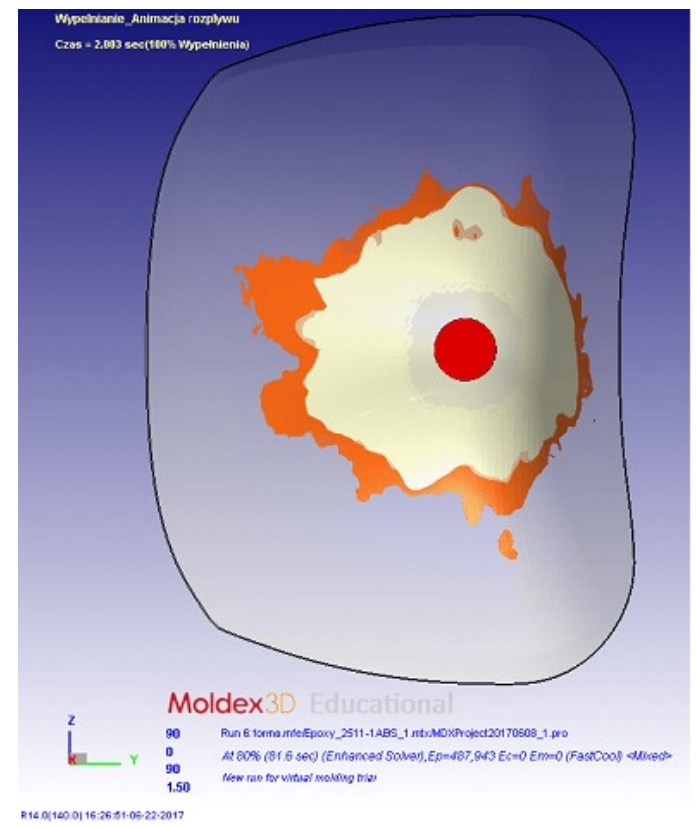

(a) 


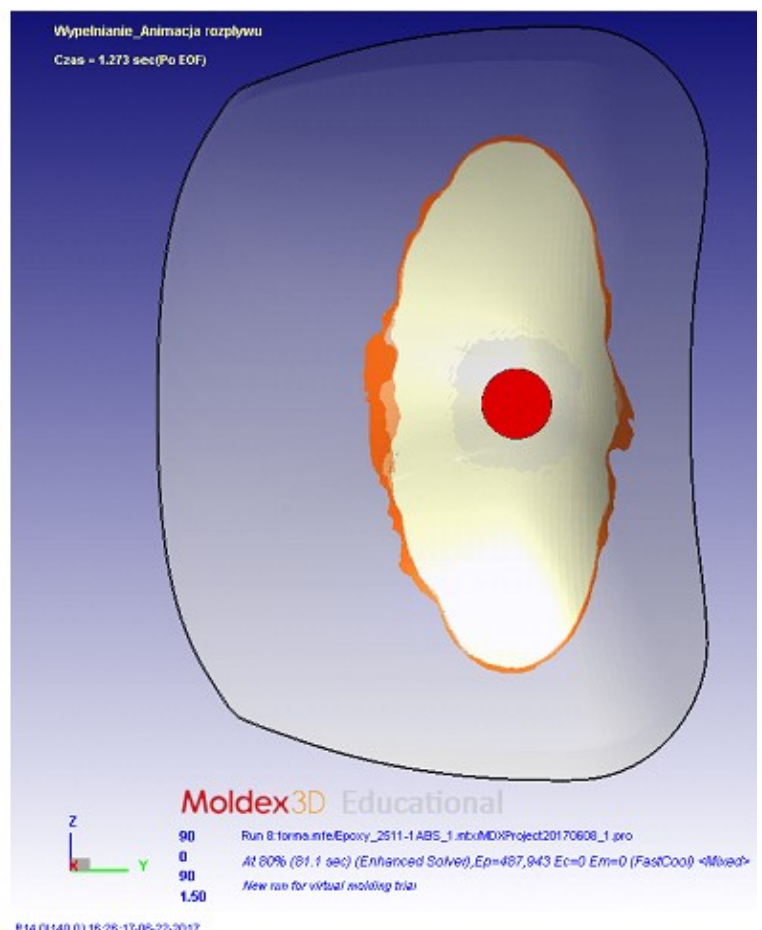

(b)

Fig. 10. Flow analysis for two different permeability tensors, first one with only one main direction and second one with two equivalent directions

\section{CONCLUSIONS}

Composite components are not often produced using the RTM method. This is because preparing the manufacturing is very expensive. However, the RTM method is the most efficient method of manufacturing of Epoxy-Carbon components presently in use.

Virtual manufacturing testing should be used to decrease the expense of applying new composite parts. The analysis of the mold filling process is mostly carried out by using FEM simulation and the choice of suitable injection parameters and appropriate mold development alternatives. By using computer simulations, cost of preparing a prototype can be reduced.

In this work, the CAD model corresponds to the actual components produced for automotive industry. The model does not incorporate the heating channels and the cooling system of the mold.

Reinforcement has an important impact on resin flow. Porosity is the most influential characteristic affecting on outcomes. The porosity defines the time of injection and how many resin is required for filling the mold. The low porosity of the fabric improves heat generation, causes extra stress and, improves mold fitting precision. While a low porosity of the reinforcement was considered to allow for a better saturation, air traps were rare.
The process of filling the mold was comparable in all the tests performed. For the tests carried out it was noted that the method of setting the fabric does not significantly affect the injection time and other parameters.

The form prepared for the production of RTM should allow to place the reinforcement in one simple slice to avoid bends and other complications of the shape. A constant thickness of the cavity should also be maintained. Changes in thickness may result in air traps occurring. If possible, thickness should be changed in important areas. To further simulate the processes involved, especially those related to the air traps, the appropriate mesh of finite elements needs to be generated in the walls of an element.

By consideration of numerical simulations during the development stage and the variant optimization of RTM parameters in the production of composite components, an adverse situation can be avoided and an excellent surface performance of the piece on both ends

of the mold can be achieved. The obtained composite element production time of about two minutes allows for competition with manufacturing of thermoplastic plastics.

\section{ACKNOWLEDGMENT}

The research is financed from financial resources from the statutory subsidy of the Faculty of Mechanical Engineering, Silesian University of Technology in 2021.

Authors would like to acknowledge: FX Carbonelements Sp. z o.o., EDS Poland Sp. z o.o., Paweł Paździor Work Project, MICHAEL Teresa Michalik and KUFIETA S.J. companies for sharing materials and providing content and technical-related supervision; special acknowledge for CoreTech System Co., LTD., producer of Moldex3D software and Biuro konstrukcyjne PawForm company for sharing educational license and for help with software.

\section{REFERENCES}

1. Paździor P, (2018), Implementation of production in the field of thermoplastic-carbon composite connections based on numerical simulations, Engineering Modeling, 37, 68.

2. Bernaciak M, (2012), Composite bonding Designing and Engineering Structures, 11, p 3-6.

3. Pramanik A, Basak AK, Dong Y, Sarker PK, Uddin MS, Littlefair G, Dixit AR and Chattopadhyaya S, (2017), Joining of carbon fibre reinforced polymer (CFRP) composites and aluminiumalloys- $A$ review, Composites Part A Applied Science and Manufacturing, 101, p 1-29. 
4. Czulak A, (2017), Composites in aviation - market analysis, Composites, 08.

5. K. Potter, (1997), Resin transfer moulding, Chapman and Hall (Bristol)

6. Ruiz E, Achim V, Lebel F, (2010), Characterization, Analysis And Design Of RTM, Process The 10th Int. Conf. Flow Processes in Composite Materials (FPCM10), (Monte Verita, Ascona.

7. Laurenzi S, Marchetti M, (2012), Advanced composite materials by resin transfer molding, Composites and Their Properties, Intech, p. 197-223, 8. Soutis C, (2005), Carbon fiber reinforced plastics in aircraft construction, Materials Science and Engineering, 412, p 171-176.

9. Mayer P, Karzmar JW, (2013), Properties and applications of carbon and glass fibers, Plastics and Chemistry p 52-6.

10. Dobrzański LA, (2002), The basics of materials science and metallurgy (WNT).

11. Kruckenberg T, Paton R, (1998), Resin transfer moulding for aerospace structures, Kluwer Academic Publishers.

12. Conversion Encyklopedia Powszechna (PWN).

13. CoreTech System Co., Ltd. (2014), Introduction of RTM, http://support.moldex3d.com, accessed at 15.01.2021.

14. Geissberger R, Maldonado J, Bahamonde N, Keller A, Dransfeld C, Masania K, (2017), Rheological modelling of thermoset composite processing, Composites Part B, p 182-189.

15. Wittemann F, Maertens R, Bernath A, Hohberg M, Kärger L, Henning F, (2018), Simulation of Reinforced Reactive Injection Molding with the Finite Volume Method,

16. Wymysłowski A, (2007), Numerical methods of thermomechanical design in electronic assembly, (Oficyna Wydawnicza Politechniki Wrocławskiej).

17. CoreTech System Co. (2014), Visualize Resin

Transfer Molding Behavior Using Advanced 3D CAE Technology, http://www.moldex3d.com, accessed at 04.02.2021.

18. Jeżowiecka-Kabsch K, Szewczyk H (2001), Fluid mechanics (Oficyna Wydawnicza Politechniki Wrocławskiej).

19. Chhabra RP and Richardson JF (1999), NonNewtonian Flow in the Process Industries, Elsevier.

20. Bhat P, Merotte J, Simacek P, Advani SG. (2004), Process analysis of compression resin transfer molding, Composites Part A: Applied Science and Manufacturing, 40(4), p 431-441.

21. Bruschke MV, Advani SG (1990), A Finite Element/Control Volume Approach to Mold Filling in Anisotropic Porous Media, Polymer Composites 11(6), p 398-405.
Received: April 12, 2021 / Accepted: December 20, 2021 / Paper available online: December 25, 2021 (C) International Journal of Modern Manufacturing Technologies 